\title{
Pengaruh Perlakuan Alkalisasi Serat Alam Kayu Bangkirai (Shorea Laevifolia Endert) pada Sifat Mekanik Komposit dengan Matriks Poliester
}

\author{
Andromeda Dwi Laksono ${ }^{1 *}$, Basyaruddin ${ }^{2}$, Nur Adlina ${ }^{3}$ \\ ${ }^{1,2,3}$ Institut Teknologi Kalimantan, Balikpapan, Indonesia \\ *E-mail: andromeda@itk.ac.id
}

\begin{abstract}
Waste of bangkirai wood is very abundant and is not currently utilized optimally. It is known that composites using natural fibers have many advantages such as the material produced is lighter, corrosion-resistant, the availability of abundant raw materials, low production costs and natural fibers are more environmentally friendly. Natural fiber composite is a solution to the utilization of bangkirai wood waste. For optimal mechanical properties, chemical treatment of bangkirai wood fiber waste is needed. This study was conducted to determine the effect of alkalization treatment of natural fibers of bangkirai wood (Shorea Laevifolia Endert) with polyester matrix on the mechanical properties of tensile and flexural strength. The making of composites was carried out using the hand lay up method with the size of tensile test specimens that referred to ASTM D 638 and bending test specimens which referred to ASTM D 790 and from the tensile test results morphological observations were performed using Scanning Electron Microscopy (SEM).The results of this study are the optimal tensile strength values of $58.33 \mathrm{MPa}$ in fiber composites with 7\% alkalization treatment. As for the optimal bending strength in bending test of $65.63 \mathrm{MPa}$ in fiber composites with $5 \%$ alkalization treatment.
\end{abstract}

Keywords :bangkirai wood, alkalization treatment, tensile test, bending test

\begin{abstract}
Abstrak
Jenis Kayu bangkirai terutama limbahnya sangat berlimpah dan saat ini belum dimanfaatkan secara optimal. Diketahui bahwa komposit menggunakan serat alam memiliki banyak keunggulan seperti material yang dihasilkan lebih ringan, tahan korosi, ketersediaan bahan baku yang melimpah, biaya produksi rendah serta serat alam lebih ramah lingkungan. Komposit serat alam merupakan solusi pemanfaatan limbah kayu bangkirai. Agar sifat mekaniknya optimal, perlu dilakukan perlakuan kimia pada limbah serat kayu bangkirai. Penelitian ini dilakukan untuk mengetahui pengaruh perlakuan alkalisasi serat alam kayu bangkirai (Shorea Laevifolia Endert) dengan matriks poliester pada sifat mekanik kekuatan tarik dan kelenturan. Pembuatan komposit dilakukan menggunakan metode hand lay up dengan ukuran spesimen uji tarik yang mengacu pada ASTM D 638 dan spesimen uji bending yang mengacu pada ASTM D 790 serta dari hasil pengujian tarik dilakukan pengamatan morfologi menggunakan Scanning Electron Microscopy (SEM).Hasil dari penelitian ini adalah nilai kekuatan tarik optimal sebesar 58,33 MPa pada komposit serat dengan perlakuan alkalisasi 7\%. Sedangkan untuk kekuatan bending optimal pada pengujian bending sebesar 65,63 MPa pada komposit serat dengan perlakuan alkalisasi 5\%.
\end{abstract}

Kata kunci :bangkirai wood, perlakuan alkalisasi, uji tarik, uji bending

\section{Pendahuluan}

Kayu bangkirai merupakan salah satu kayu yang banyak digunakan masyarakat. Kayu bangkirai atau disebut Shorea Laevifolia
Endert merupakan jenis kayu dengan kategori kelas awet I-II dan kelas kuat I-II dengan berat jenis $0,6-1,13 \mathrm{~kg} / \mathrm{m}^{3}[1]$. Kayu bangkirai biasanya digunakan untuk konstruksi 
jembatan, perkapalan, kerajinan untuk perumahan dan bahan bakar [2]. Namun untuk limbah dari kayu bangkirai untuk saat ini belum dimanfaatkan secara optimal.

Komposit terdiri dari dua unsur utama yang biasa disebut dengan matriks dan penguat (reinforcement). Matriks merupakan fasa pada bagian komposit yang mempunyai fraksi volume terbesar. Matriks berfungsi sebagai pengikat partikel yang digunakan, dengan tujuan agar partikel tetap berada pada tempatnya. Selain itu, matriks juga berfungsi sebagai distributor tekanan dan pelindung serat [3]. Reinforcement merupakan bahan dalam komposit yang berfungsi sebagai penguat. Reinforcement dapat berupa laminar, partikel dan serat.Penggunaan material komposit merupakan salah satu solusi dalam mengganti suatu material konvensional seperti logam, keramik, kayu, dan polimer. Komposit memiliki kelebihan seperti ringan, tahan korosi serta kekuatan dan kekakuan tertentu. Saat ini, penggunaan material komposit dalam masyarakat telah menjadi sangat umum dan material komposit biasanya ditemukan dalam furnitur, transportasi, pendidikan, olahraga dan lain sebagainya [4]. Dengan teknologi komposit, dapat menggabungkan antara penguat dari serat alam dan pengikat dari polimer tertentu. Serat alam memiliki sifat biodegradable dan akan memiliki nilai tambah bila limbah serat alam dapat dimanfaatkan dengan baik untuk komposit.

Hal ini yang menjadi dasar dilakukannya penelitian komposit dengan serat alam dengan menggunakan kayu bangkirai. Material penyusun komposit dalam penelitian ini menggunakan poliester dan kayu bangkirai. Pada umumnya serat alam bersifat hidrophilik yang dimana polimer bersifat hidrophobik. Hal ini dapat mempengaruhi ikatan antara matriks dan serat alam. Dengan perlakuan alkalisasi menggunakan $\mathrm{NaOH}$ dapat mengurangi sifat hidrophilik serat alam sehingga memiliki kompatibilitas dengan bahan-bahan hidrophobik polimer. Perlakuan alkalisasi berfungsi untuk melarutkan zat pada serat alam seperti lignin dan kotoran (impuritas) sehingga dapat meningkatkan ikatan antara matriks dan serat alam [5]. Resin poliester digunakan karena dapat berikatan dengan serat alam tanpa menimbulkan reaksi dan gas. Tujuan penelitian ini adalah untuk mengetahui sifat mekanik pada material komposit serat alam kayu bangkirai dengan matriks poliester untuk bilah kincir angin dengan mengukur kekuatan tarik dan kekuatan lentur dari komposit serat alam.

\section{Metodologi}

\subsection{Alat dan Bahan}

Alat-alat yang digunakan dalam penelitian ini terdiri dari pengaduk, cetakan specimen, timbangan digital, wadah pengaduk, dan gelas kimia.

Sedangkan bahan yang digunakan yaitu limbah kayu bangkirai dengan bentuk serutan kayu yang diketam dengan ukuran $10 \mathrm{~mm}$. Polimer yang digunakan sebagai matriks komposit yaitu resin Poliester tak jenuh. Adapun katalis digunakan untuk mempercepat reaksi yang terjadi antara resin dan pengisi. Kemudian lainnya yaitu $\mathrm{NaOH}$ kristal dengan konsentrasi 3\%, 5\% dan 7\% serta aquades.

\subsection{Persiapan Serat Alam Kayu Bangkirai}

Serutan kayu bangkirai dibersihkan dari kotoran yang menempel dan dipotong dengan ukuran $10 \mathrm{~mm}$. Kayu yang sudah di potongkemudian dilakukan perlakuan kimia (alkalisasi) menggunakan larutan alkali $\mathrm{NaOH}$ dengan konsentrasi 3\%, 5\% dan $7 \%$ yang masing-masing dilakukan perendaman selama 1 jam. Kemudian serat kayu dicuci menggunakan aquades untuk menghilangkan sisa dari $\mathrm{NaOH}$. Selanjutnya serat dikeringkan dengan menggunakan oven pada temperatur $100{ }^{\circ} \mathrm{C}$ selama 1 jam 30 menit.Serat kayu bangkirai setelah perlakuan alkali ditunjukkan pada Gambar 1.

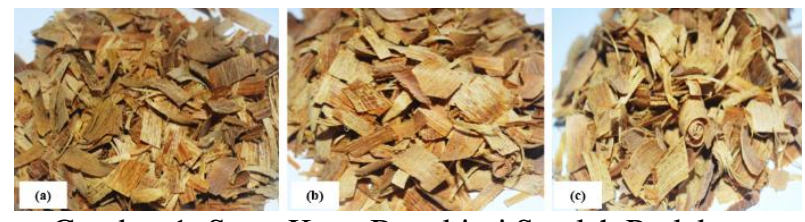

Gambar 1. Serat Kayu Bangkirai Setelah Perlakuan

Alkali dengan Konsentrasi (a) 3\%, (b) 5\%, dan (c) 7\% 


\subsection{Pembuatan Komposit}

Penelitian ini menggunakan komposit berbahan dasar serutankayu bangkirai dan resin poliester. Pembuatan komposit dilakukan dengan metode hand lay updengan perbandingan fraksi volume $30 \%$ serat dan $70 \%$ matrik resin poliester. Pembuatan komposit dimulai dengan menyusun serutan pada cetakan kemudian dilakukan penuangan resin ke dalam cetakan lalu ditambahkan katalis $1 \%$ dan ditekan dengan spatula hingga rata. Setelah rata, sampel cetakan baik untuk uji tarik maupun uji bendingdikeringkan komposit di temperatur ruang selama satu hari.

\subsection{Pengujian Sifat Mekanik dan Morfologi}

Dilakukan dua pengujian sifat mekanik pada penelitian ini yaitu uji bending dan uji tarik. Pengujian bending dilakukan untuk mengetahui sifat mekanik yaitu kelenturan dari sampel. Pada pengujian bending menggunakan standar ASTM D 790. Sedangkan pengujian tarik dilakukan untuk mengetahui sifat mekanik dasi sampel yaitu kekuatan tarik. Pada pengujian tarik menggunakan standar ASTM D 638. Untuk pengamatan patahan setelah uji tarik, dilakukan pengujian morfologi pada komposit menggunakan SEM (Scanning Electron Microscopy). Pengamatan SEM dilakukan dengan tujuan untuk mengamati morfologi pada komposit serta distribusi dan dispersi serat dan matriks pada patahan spesimen.

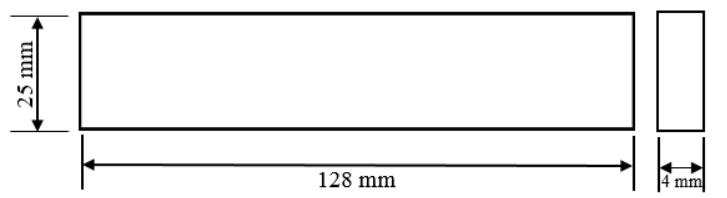

Gambar 2. Dimensi Spesimen Uji Bending

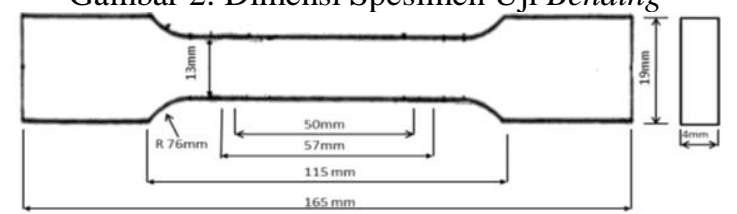

Gambar 3. Dimensi Spesimen Uji Tarik

\section{Hasil dan Pembahasan}

\subsection{Hasil Pembuatan Komposit}

Dari Gambar 4 merupakan hasil pembuatan komposit pada sampel uji tarik.
Terdapat perbedaan warna lebih terang pada kayu bangkirai (Gambar 4(a)) dengan kayu bangkirai setelah dijadikan komposit (Gambar 4(b-e)). Sedangkan sampel tanpa perlakuan alkali dan dengan diberi perlakuan alkali tidak memiliki perbedaan secara visual. Hal yang sama juga terjadi pada sampel uji bending pada Gambar 5.
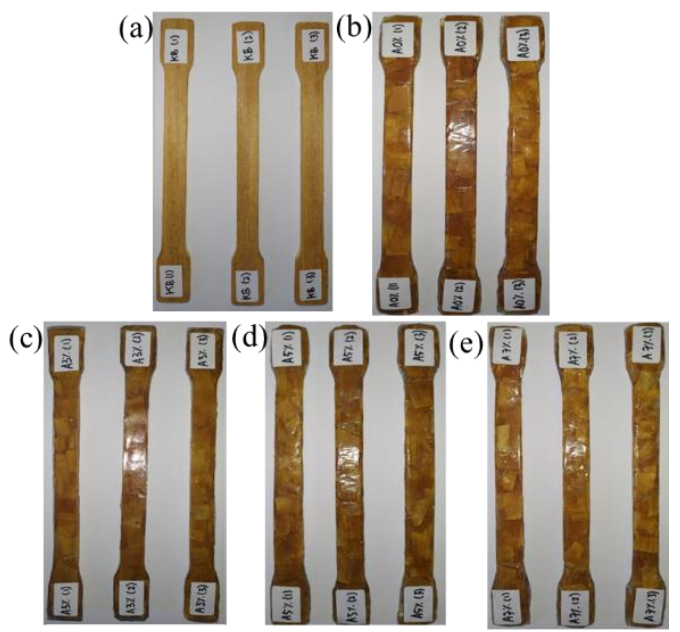

Gambar 4. Spesimen Uji Tarik (a) Kayu Bangkirai, (b) Tanpa Perlakuan Alkali, (c) Perlakuan Alkali 3\%, (d) Perlakuan Alkali 5\%, dan (e) Perlakuan Alkali 7\%
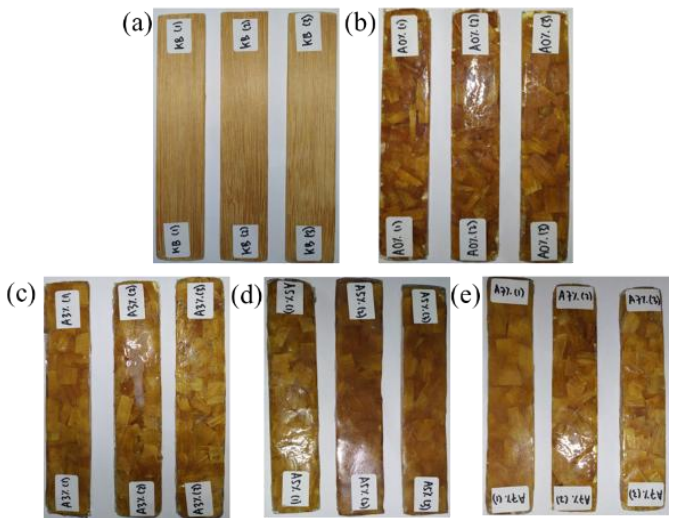

Gambar 5. Spesimen Uji Bending (a) Kayu Bangkirai,

(b) Tanpa Perlakuan Alkali, (c) Perlakuan Alkali 3\%,

(d) Perlakuan Alkali 5\%, dan (e) Perlakuan Alkali 7\%

\subsection{Hasil Pengujian Tarik}

Dalam penelitian ini dilakukan beberapa pengujian tarik secara terpisah yaitu pengujian tarik untuk bahan kayu bangkirai dan komposit yang dihasilkan.Pengujian ini dilakukan untuk mengetahui pengaruh perlakuan alkalisasi pada sifat mekanik yaitu kekuatan tarik dari komposit kayu bangkirai. Pada Tabel 1,dapat dilihat bahwa nilai kekuatan tarik $(\sigma)$ tertinggi 
dimiliki oleh komposit serat dengan diberi perlakuan alkali 7\% dengan nilai sebesar 58,33 $\mathrm{MPa}$. Pengaruh penambahan alkalisasi $(\mathrm{NaOH})$ komposit serat alam dan poliester dapat menambah nilai kekuatan tarik [6].

Tabel 1. Data Hasil Pengujian Uji Tarik

\begin{tabular}{ccc}
\hline Sampel & $\begin{array}{c}\text { Beban } \\
\text { Maksimal } \\
\text { (N) }\end{array}$ & $\begin{array}{c}\text { Kekuatan } \\
\text { Tarik } \\
\text { (MPa) }\end{array}$ \\
\hline $\begin{array}{c}\text { Tanpa } \\
\text { Perlakuan } \\
\text { Alkali }\end{array}$ & 2600 & 50 \\
Perlakuan & & \\
Alkali & 2566,67 & 49,36 \\
3\% & & \\
Perlakuan & & \\
Alkali & 2933,33 & 56,41 \\
5\% & & \\
Perlakuan & & \\
Alkali & 3033,33 & 58,33 \\
7\% & & \\
Murni & & \\
Kayu & 6433,33 & 123,72 \\
Bangkirai & & \\
\hline
\end{tabular}

Pada Gambar 6, komposit tanpa perlakuan alkali maupun dengan perlakuan alkali memiliki kekuatan tarik yang masih lebih rendah dibandingkan dengan kekuatan tarik pada bahan serat dari komposit yaitu kayu bangkirai dengan nilai kekuatan tarik sebesar 123,72 $\mathrm{MPa}$. Hal ini dapat dikatakan bahwa komposit serat alam kayu bangkirai dengan penambahan konsentrasi $\mathrm{NaOH}$ pada perlakuan alkali berpengaruh untuk meningkatkan sifat mekanik kekuatan tarik komposit, tetapi nilai kekuatan tarik komposit tidak dapat mencapai bahan dari komposit ini sendiri yaitu kayu bangkirai.

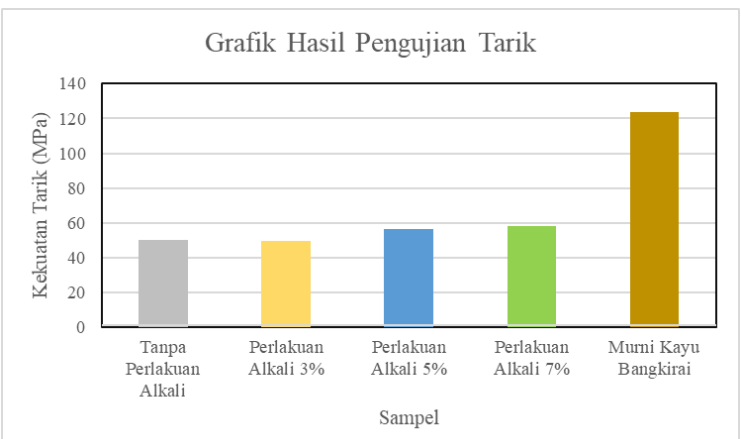

Gambar 6. Grafik Rata-rata Kekuatan Tarik

\subsection{Hasil Pengujian Bending}

Pengujian yang dilakukan dengan menggunakan alat mesin uji bending jenis three-point bending.Pada Tabel 2, nilai kekuatan bending $\left(\sigma_{\mathrm{b}}\right)$ tertinggi dimiliki oleh kayu bangkirai dengan nilai sebesar 167,13 $\mathrm{MPa}$. Sedangkan pada sampel komposit yang memiliki nilai kekuatan bending tertinggi ialah komposit yang diberi perlakuan alkali dengan konsentrasi 5\% dengan nilai 65,63 $\mathrm{MPa}$.

Tabel 2. Data Hasil Pengujian Uji Bending

\begin{tabular}{|c|c|c|}
\hline Sampel & $\begin{array}{c}\text { Beban } \\
\text { Maksimal } \\
(\mathbf{N})\end{array}$ & $\begin{array}{c}\text { Kekuatan } \\
\text { Bending } \\
\text { (MPa) }\end{array}$ \\
\hline $\begin{array}{c}\text { Tanpa } \\
\text { Perlakuan } \\
\text { Alkali }\end{array}$ & 16,67 & 4,38 \\
\hline $\begin{array}{l}\text { Perlakuan } \\
\text { Alkali 3\% } \\
\text { Perlakuan }\end{array}$ & 156,67 & 41,13 \\
\hline $\begin{array}{l}\text { Alkali 5\% } \\
\text { Perlakuan }\end{array}$ & 250 & 65,63 \\
\hline $\begin{array}{l}\text { Alkali 7\% } \\
\text { Murni Kayu }\end{array}$ & 90 & 23,63 \\
\hline Bangkirai & 636,67 & 167,13 \\
\hline
\end{tabular}

Bila dilihat Gambar 8, dapat diketahui hasil kekuatan bending bahwa dengan diberinya perlakuan alkali pada komposit serat bangkirai-poliester berpengaruh signifikan pada kekuatan bendingnya. Perlakuan alkali dapat meningkatkan ikatan antara serat dan matriks[7]. Namun seiring terus bertambahnya pengaruh alkali, tidak kontinu meningkatkan kekuatan bending. Hasil pengujian bending untuk komposit didapatkan kekuatan bending yang paling optimal ialah pada perlakuan alkali 5\%, sedangkan nilai kekuatan bending menurun pada komposit dengan perlakuan alkali 7\%.Berdasarkan penelitian dari Maryanti dkk. mengenai pengaruh alkalisasi komposit serat kelapa-poliester terhadap kekuatan tarik menjelaskan bahwa hemiselulosa, lignin dan selulosa juga akan ikut terlarut sehingga kekuatan serat alam akan menurun [6]. Dimungkinkan dengan semakin meningkatnya konsentrasi alkali yang berlebihan dapat menghilangkan sebagian lignin dari serat kayu bangkirai yang merupakan kekuatan serat alam komposit. 
Dapat diartikan juga bahwa kondisi sudah mencapai jenuh pada perlakuan alkali $7 \%$. Selain itu, dari pengamatan secara visual yang dilakukan spesimen komposit dengan perlakuan alkali $3 \%$ dan $7 \%$ terdapat void(ditandai dengan lingkaran hitam pada Gambar 7) yang lebih besar dibandingkan dengan spesimen perlakuan alkali 5\%.Hal ini mengakibatkan komposit mengalami penurunan kekuatan bending dan modulus elastisitas dimana semakin banyak dan besarnya bentuk void dapat menurunkan sifat mekaniknya[8]. Dari Gambar 8, komposit bending dengan perlakuan $3 \%$ dan $7 \%$ mengalami penurunan.

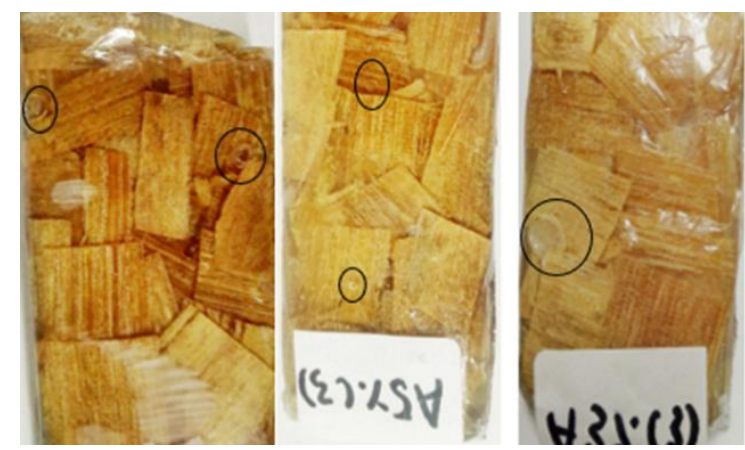

Gambar 7. Pengamatan Visual pada Spesimen Bending (a) Perlakuan Alkali 7\%, (b) Perlakuan Alkali 5\%, dan (c) Perlakuan Alkali 3\%

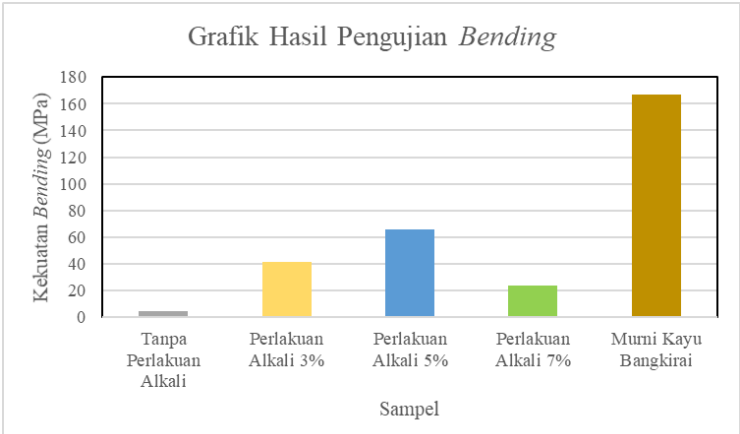

Gambar 8. Grafik Rata-rata Kekuatan Bending

\subsection{Hasil Pengujian SEM}

Pengujian SEM dilakukan untuk mengamati morfologi komposit pada patahan spesimen uji tarik. Gambar 9 merupakan hasil dari pengujian SEM bagian patah uji tarik dari komposit serat kayu bangkirai tanpa perlakuan alkali dan komposit serat kayu bangkirai dengan perlakuan alkali yang paling optimal yaitu komposit perlakuan alkali 7\%. Dari hasil pengamatan SEMterlihat perbedaan morfologi permukaan serat kayu bangkirai yaitu pada Gambar 9(a) terlihat serat kayu bangkirai memiliki permukaan serat yang lebih halusdibandingkan dengan serat kayu bangkirai dengan perlakuan alkali pada Gambar 9(b) yang memiliki permukaan lebih kasar. Hal ini dikarenakan serat kayu bangkirai tanpa perlakuan alkali masih terdapat lapisan lignin dan zat pengotor yang membuat ikatan antara serat dan matriks tidak menyatu dengan baik. Sedangkan lapisan lignin dan zat pengotor pada serat kayu bangkirai yang diberi perlakuan alkali akan terlarut saat diberi perlakuan yang mengakibatkan permukaan serat menjadi lebih kasar. Permukaan serat yang kasar dapat meningkatkan ikatan antara serat dan matriks yang membuat kekuatan tarik lebih baik [9].
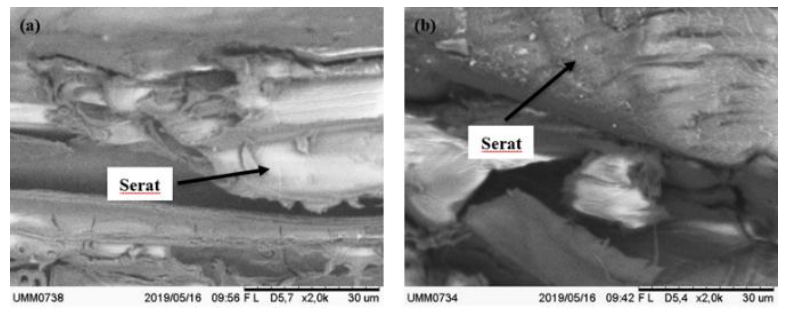

Gambar 9.Foto SEM Permukaan Perbesaran 2000 x pada Komposit (a) Tanpa Perlakuan dan (b) Perlakuan Alkali 7\%

Hasil SEM pada Gambar 10 ialah bagian patah uji tarik dari komposit serat kayu bangkirai tanpa perlakuan. Dari pengamatan morfologi mengindikasikan adanya debonding antara matriks dengan serat dan interfacial gap yang menunjukkan bahwa ikatan antara serat dan matriks tidak baik. Selain itu terdapat lumen yang dapat mempertahankan struktur serat dan bentuk dinding sel yang masih utuh serta halus mengindikasikan masih terdapatnya lignin dan hemiselulosa pada serat yang digunakan.

Sedangkan pada Gambar 11 ialah hasil SEM yang diamati bagian patah uji tarik dari komposit serat kayu bangkirai dengan perlakuan alkali 7\%. Dari pengamatan morfologi mengindikasikan adanya debonding antara maktriks dan pengisi (filler). Adanya debonding menyebabkan matriks terjadi 
cracking[10].Debonding terjadi akibat pemutusan serat pada saat uji tarik yang terjadi di daerah interface dari serat dan matriks yang kemudian dapat merambat pada debonding lainnya mengakibatkan satu patahan besar pada komposit.

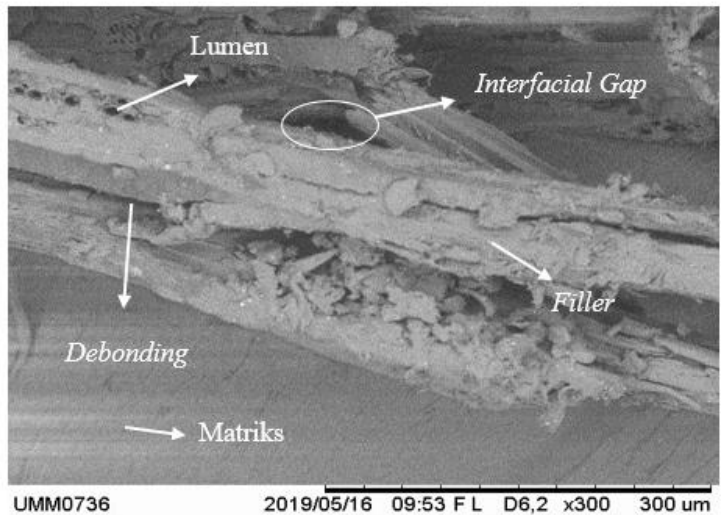

Gambar 10.Hasil Pengujian SEM Komposit Tanpa Perlakuan dengan Perbesaran 300x

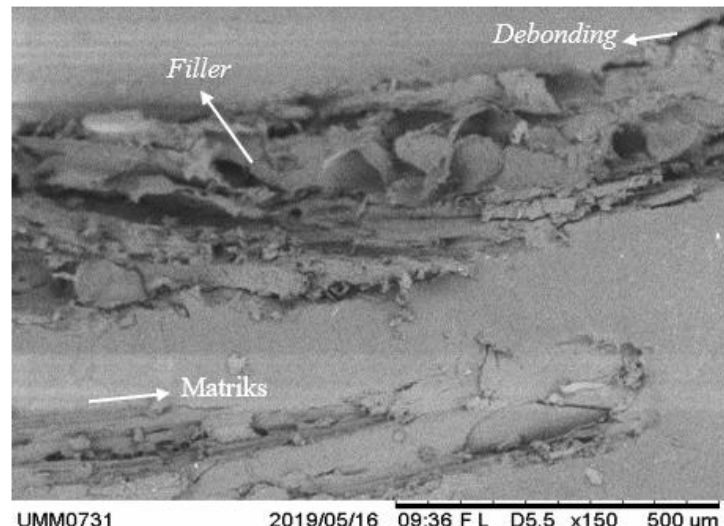

Gambar 11.Hasil Pengujian SEM Komposit Perlakuan Alkali 7\% dengan Perbesaran 150x

\section{Kesimpulan}

Perlakuan alkalisasi terhadap komposit serat bangkirai mempengaruhi sifat mekanik yaitu sifat kekuatan tarik dan kekuatan bending dimana komposit yang diberi perlakuan alkali memiliki nilai yang lebih tinggi dibandingkan serat yang tidak diberi perlakuan alkali. Nilai optimum untuk kekuatan tarik terdapat pada komposit dengan perlakuan alkali 7\% sebesar 58,33 $\mathrm{MPa}$ Sedangkan untuk kekuatan bending terdapat pada komposit dengan perlakuan alkali 5\% sebesar 65,63 MPa Nilai. Hasil pengujian SEM yang dilakukan terhadap masing-masing komposit yang tanpa perlakuan alkali menunjukkan serat bangkirai lebih halus dibandingkan dengan perlakuan alkali konsentrasi $7 \%$

\section{Saran}

Diperlukan perlakuan kimia lainnya seperti (bleching) pada serat kayu agar dapat meningkatkan nilai sifat mekanik pada komposit dan penambahan pengujian FTIR (Fourier-transform Infrared Spectroscopy) terhadap komposit serat untuk mengetahui pengaruh dari perlakuan kimia pada serat secara akurat.

\section{Ucapan Terimakasih}

Penulis mengucapkan terima kasih kepada Lembaga Penelitian dan Pengabdian Masyarakat (LPPM) ITK dan Direktorat Riset dan Pengabdian Masyarakat, Direktorat Jenderal Penguatan Riset dan Pengembangan, Kementerian Riset, Teknologi, dan Pendidikan Tinggi yang telah memberikan banyak dukungan dalam penelitian ini.

\section{Daftar Pustaka}

[1] H. Boesono, "Pengaruh lama perendaman terhadap organisme penempel dan modulus elastisitas pada kayu," Ilmu Kelautan, vol. 13, no. 3, pp. 177-180, 2008.

[2] A. Martawijaya, "Atlas Kayu Indonesia," 2004.

[3] D. W. I. A. Kurniawan, "Unjuk Kerja Turbin Angin Propeller 4 Sudu Berbahan Komposit Berdiameter $100 \mathrm{Cm}$, Dengan Lebar Maksimum Sudu 13 Cm Pada Jarak 19 Cm Dari Pusat Sumbu Poros." Skripsi. Universitas Sanata Dharma. Yogyakarta, 2016.

[4] S. M. Sapuan, "Chapter 1 - Introduction," S. M. B. T.-C. M. Sapuan, Ed. Boston: Butterworth-Heinemann, 2017, pp. 1-27.

[5] E. Syafri, A. Kasim, H. Abral, and A. Asben, "Pengaruh Chemical Treatment Terhadap Sifat Fisik, Kandungan Selulosa Dan Kekuatan Tarik Serat Alam Rami," Jurnal Teknologi Pertanian Andalas, vol. 19, no. 2, pp. 18-24, 2015.

[6] B. Maryanti, A. A. ad Sonief, and S. Wahyudi, "Pengaruh Alkalisasi Komposit Serat Kelapa-Poliester Terhadap Kekuatan 
Tarik," Rekayasa Mesin, vol. 2, no. 2, pp. 123-129, 2011.

[7] Y. Y. Pratama, R. H. Setyanto, and I. Priadythama, "Pengaruh Perlakuan Alkali, Fraksi Volume Serat, dan Panjang Serat terhadap Kekuatan Tarik Komposit Serat Sabut Kelapa-Polyester," 2014.

[8] Z. Zulkifli, H. Hermansyah, and S. Mulyanto, "Analisa Kekuatan Tarik dan Bentuk Patahan Komposit Serat Sabuk Kelapa Bermatriks Epoxyterhadap Variasi Fraksi Volume Serat," JTT (Jurnal Teknologi Terpadu), vol. 6, no. 2, pp. 9095, 2018.

[9] A. Fathoni, W. W. Raharjo, and T. Triyono, "Pengaruh Perlakuan Panas Serat Terhadap Sifat Tarik Serat Tunggal dan Komposit Cantula-rHDPE," Simetris: Jurnal Teknik Mesin, Elektro dan Ilmu Komputer, vol. 8, no. 1, pp. 67-74, 2017.

[10] F. E. Gunawan, H. Homma, And S. Shirley, "An Analysis of Debonding along Interface of Bundled Fibers and Matrix," Journal of Solid Mechanics and Materials Engineering, vol. 2, no. 3, pp. 310-318, 2008. 